\title{
FOXO3a: a novel player in thyroid carcinogenesis?
}

\author{
Stefan Karger*, Carl Weidinger*, Kerstin Krause, Sien-Yi Sheu ${ }^{1}$, \\ Thomas Aigner ${ }^{2}$, Oliver Gimm ${ }^{3}$, Kurt-Werner Schmid ${ }^{1}$, Henning Dralle ${ }^{3}$ \\ and Dagmar Fuhrer
}

\author{
Division of Endocrinology and Diabetes, Department of Internal Medicine, University of Leipzig, Ph.-Rosenthal-Street 27, 04103 \\ Leipzig, Germany \\ ${ }^{1}$ Institute of Pathology and Neuropathology, University of Duisburg-Essen, Essen, Germany \\ ${ }^{2}$ Institute of Pathology, University of Leipzig, Leipzig, Germany \\ ${ }^{3}$ Department of Surgery, University of Halle-Wittenberg, Halle, Germany \\ (Correspondence should be addressed to D Fuhrer; Email: fued@medizin.uni-leipzig.de) \\ *(S Karger and C Weidinger contributed equally to this study)
}

\begin{abstract}
The forkhead box transcription factor FOXO3a has recently been identified as central mediator of the cellular response to oxidative stress inducing cell cycle arrest or apoptosis. The aim of our study was to investigate the regulation of $\mathrm{FOXO} 3 \mathrm{a}$ in the thyroid and to determine whether alterations in $\mathrm{FOXO} 3 a$ activity occur in thyroid carcinogenesis. In vitro, we demonstrate that $\mathrm{FOXO} 3 \mathrm{a}$ activity is negatively regulated by the PI3K/Akt cascade promoting increased phosphorylation and cytoplasmatic accumulation of $\mathrm{FOXO} 3 a$ with decreased transcription of the target genes p27kip (CDKN1B) and Bim (BCL2L11), but increased expression of GADD45A. By contrast, we show that $\mathrm{H}_{2} \mathrm{O}_{2}$ exposure activates FOXO3a in thyrocytes with JNK (MAPK8)-mediated nuclear accumulation of $\mathrm{FOXO} 3 \mathrm{a}$ and increased expression of the cell cycle arrest genes p27kip and GADD45A. In vivo, we observed a marked cytoplasmatic accumulation of FOXO3a in differentiated thyroid cancers versus an exclusive nuclear accumulation in follicular adenoma and normal thyroid tissue. Moreover, this cytosolic accumulation of FOXO3a correlated with an increased phospho-Akt expression in thyroid malignancies and was accompanied by decreased expression of the FOXO targets p27kip and Bim and an increase in GADD45A mRNA expression in the thyroid cancers. Our data suggest FOXO3a as a novel player of cellular stress response in the thyroid, mediating the thyrocyte's fate either to survive or to undergo apoptosis. Furthermore, PI3K-dependent FOXO3a inactivation may be a novel pathomechanism for the escape from apoptosis in thyroid cancer cells, in particular in follicular thyroid carcinoma.
\end{abstract}

Endocrine-Related Cancer (2009) 16 189-199

\section{Introduction}

Growth factor-induced cellular proliferation depends on specific survival signaling (Birkenkamp \& Coffer 2003, van der Horst \& Burgering 2007). In the absence of survival signals, cells do not proliferate but rather undergo apoptosis. Mutations in regulatory cell cycle genes may disturb the cellular homeostasis existing between proliferation and apoptosis, and cells may escape controlled growth (Bartkova et al. 2005, Essers et al. 2005).

Recently, the subclass $\mathrm{O}$ of forkhead transcription factors $(\mathrm{FOXO})$ have been linked to the regulation of cellular proliferation and apoptosis: FOXOs promote tumor suppression by the induction of proteins mediating cell cycle arrest, apoptosis, and DNA damage repair. In addition, they regulate cellular longevity by exerting resistance to oxidative stress and metabolic adaptation to nutritional deprivation (Essers et al. 2005, Greer et al. 2007). To date, four different isoforms of FOXOs are known in mammals and are termed FOXO1, FOXO3a, FOXO4, and FOXO6 (Huang \& Tindall 2006).

FOXO3a is localized in the nucleus, where it activates or represses the transcription of target genes. Upon stimulation with growth factors FOXO3a is 
phosphorylated, which accelerates the nuclear exclusion of FOXO3a, thereby inhibiting its ability to bind DNA. The nuclear export of FOXO3a is mediated by 14-3-3 proteins and exportins, e.g., CRM1, which also prevent the nuclear reimport of FOXO3a (Birkenkamp \& Coffer 2003, van der Heide et al. 2004). Besides phosphorylation, FOXO proteins can undergo further posttranslational modifications such as acetylation and deacetylation. These steps are mandatory for the specificity of FOXO protein activity, which is reflected by distinct target gene expression such as Bim (BCL2L11), p27kip (CDKN1B), and GADD45A (Brunet et al. 2004). Posttranslational inactivation of FOXO3a with combined nuclear exclusion and target gene dysregulation has been observed in several types of cancer. Thus, dysregulation of the FOXO3a target genes Bim, p27kip, and GADD45A with combined cytoplasmatic FOXO3a has been found in breast, lung, and prostate cancers. Bim has been described to be one of the major target genes of FOXO3a and is critical for the release of mitochondrial cytochrome $c$, and therefore of pivotal importance for the apoptotic program (Dijkers et al. 2000a). The FOXO target p27kip inhibits cyclin E/CDK2 complexes at the G1/S boundary of the cell cycle, which drives cells from growth into the state of cellular quiescence (Dijkers et al. 2000b, Stahl et al. 2002, Lee et al. 2006, van der Horst \& Burgering 2007). GADD45A plays an important role in the control of cell cycle checkpoints and DNA repair (Hildesheim et al. 2002, Gupta et al. 2006, Tront et al. 2006). For example, GADD45A can block the formation of cyclin/CDK complexes at the G2/M-phase boundary, resulting in growth arrest. Furthermore, GADD45A was described to act as a base excision protein in response to ionizing irradiation.

Thyroid epithelial neoplasia represents a unique entity, since tumors with very different functional and histological characteristics, malignant potential, and degrees of differentiation can arise from a single ancestor cell (Fagin 2002). The event determining the different phenotypes, e.g., hyper- and hypo-functioning thyroid nodules, and benign and malignant thyroid tumors, appears to differ from the point of the clonal initiation. Specific genetic alterations involved in thyroid tumorigenesis have been identified mainly in malignant thyroid tumors, notably RET-PTC transgenes, BRAF V600E mutations in papillary thyroid cancers, PAX8-PPARG rearrangements, and retrovirus-associated DNA sequences (RAS) mutations in the subsets of follicular thyroid cancers and RET-proto-oncogene mutations in medullary thyroid cancers (Kroll et al. 2000, Fagin 2002, Nikiforova et al. 2003, Santoro et al. 2004).
Presently, a pivotal role of oxidative stress is discussed in thyroid physiology and disease (Krause et al. 2007b, Song et al. 2007), and has been found to be consistent with an increase in mutagenesis in the thyroid (Maier et al. 2006). In addition, we have recently observed increased levels of oxidative DNA damage in thyroid cancers, notably in follicular thyroid carcinoma (FTC; Karger S, et al. unpublished observations).

In view of the critical role that FOXOs play in oxidative stress defense, it might be possible that alterations of FOXO function by inhibition of FOXO activity or of its transcriptional activity may result in increased oxidative stress and an imbalance between proliferation and apoptosis. Therefore, the aim of this paper was to study the regulation of FOXO3a in the thyroid and to investigate $\mathrm{FOXO} 3 \mathrm{a}$ expression and function in benign and malignant thyroid tumors.

\section{Materials and methods}

\section{Thyroid samples}

Duplicates of 22 hypofunctional follicular adenomas (FA), 22 corresponding normal thyroid tissues of the same patient normal tissue (NT), 14 FTC, and 10 classic PTC were studied for mRNA expression of FOXO3a, p27kip, Bim, and GADD45A. For immunohistochemical analysis of both FOXO3a and phospho-Akt (pAkt) protein expression, paraffin-embedded tissue sections from 65 FA, 68 FTC, and 63 PTC with adjacent normal thyroid tissue and 19 NT were used. Thyroid samples were obtained from the Department of Surgery, University of Halle-Wittenberg, Halle, Germany, local Leipzig hospitals and the Institute of Pathology and Neuropathology, University of Duisburg-Essen, Essen, Germany. Patient data and clinical characteristics are available upon request. Informed consent was obtained from all patients and the local ethics committee approved the study.

\section{Cell culture}

Follicular rat thyroid cells (FRTL-5 cells (AmbesiImpiombato et al. 1980); kindly provided by Prof. Di Lauro, Naples) were split into 6-well plates $\left(3 \times 10^{5} /\right.$ well $)$ and were cultured in a 2:1:1 mixture of DMEM:Ham's F12:MCDB104 (all from Gibco Life Technologies) supplemented with 5\% newborn calf serum (NCS; Gibco Life Technologies), $10 \mu \mathrm{g} / \mathrm{ml}$ insulin, $0.4 \mu \mathrm{g} / \mathrm{ml}$ hydrocortisone (Calbiochem, San Diego, CA, USA), $45 \mu \mathrm{g} / \mathrm{ml}$ ascorbic acid (Sigma), $5 \mu \mathrm{g} / \mathrm{ml}$ transferrin (Calbiochem), and $5 \mathrm{mU} / \mathrm{ml}$ bovine TSH (Sigma) until 70\% confluence. 
Prior to TSH, insulin, and NCS stimulation, FRTL-5 cells were starved for $48 \mathrm{~h}$ in the medium containing $0.2 \%$ serum but no TSH and insulin. Afterward, the cells were incubated in the presence of either $10 \mathrm{mU} / \mathrm{ml} \mathrm{TSH}, 100 \mathrm{ng} / \mathrm{ml}$ insulin, or $5 \% \mathrm{NCS}$ for $8 \mathrm{~h}$. For controls, starving medium was changed and the cells remained in fresh starving. After the incubation period, the cells were washed with ice-cold PBS and were shock frozen in liquid nitrogen and stored at $-80{ }^{\circ} \mathrm{C}$ until further use.

For stimulation or inhibition of protein kinases, the cells were split into 6-well plates as described above and were grown in insulin and NCS containing growth media until $70 \%$ confluence. Then, either $10 \mathrm{mU} / \mathrm{ml}$ $\mathrm{TSH}, 10 \mu \mathrm{M}$ forskolin (all from Sigma-Aldrich), $10 \mu \mathrm{M}$ LY294002 (PI3K inhibitor), $1 \mu \mathrm{M}$ PMA (PKC activator), or $20 \mu \mathrm{M}$ GF10923X (PKC inhibitor; all from Calbiochem) were directly added into growth media, whereas controls were treated with dimethyl sulfoxide (DMSO) only. After stimulation, the cells were washed twice with PBS and were shock frozen in liquid nitrogen and stored at $-80{ }^{\circ} \mathrm{C}$.

\section{RNA extraction and RT-PCR}

RNA was isolated from snap-frozen thyroid tissue using TRIzol reagent (Invitrogen). One microgram of RNA per sample was reverse transcribed in a final mixture of $5 \times$ first-strand buffer $(250 \mathrm{mM}$ Tris- $\mathrm{HCl}$ (pH 8.3), $375 \mathrm{mM} \mathrm{KCl,} 15 \mathrm{mM} \mathrm{MgCl} 2$; Gibco BRL), $0.5 \mathrm{mM}$ dNTPs, $5 \mathrm{mM}$ DTT (Gibco BRL), 15 U Prime RNase inhibitor (PeqLab, Erlangen, Germany), $0.5 \mu \mathrm{g}$ random hexamer primers, and $200 \mathrm{U}$ Moloney murine leukemia virus reverse transcriptase (Gibco BRL). Reverse transcription was performed at $37^{\circ} \mathrm{C}$ for $60 \mathrm{~min}$ and $94{ }^{\circ} \mathrm{C}$ for $5 \mathrm{~min}$.

\section{Quantitative real-time PCR}

Real-time PCR was performed using the LightCycler System (Roche). Exon/intron spanning primers were designed to quantitatively calculate human and rat FOXO3a, p27kip, GADD45A, and Bim mRNA expression (primers and PCR conditions available on request). The mRNA expression of the housekeeping protein $\beta$-actin and ribosomal rs 6 protein were used for normalization of human samples and for standardization of FRTL-5 cells respectively (Eszlinger et al. 2005, Krause et al. 2007a,b).

To quantify changes in mRNA expression patterns, real-time PCR was performed using the LightCycler DNA Master SYBR Green I kit (Roche), as described previously (Krause et al. 2007a,b). Fold upregulation or downregulation of mRNA expression was calculated as follows: $n=2$ (threshold cycle of target gene NT-DT)/2(threshold cycle $\beta$-actin NT-DT). 'Diseased tissue' (DT) corresponds to FA, FTC, and PTC, whereas 'normal tissue' corresponds to the surrounding tissue of FA. The Mann-Whitney $U$-test within the SPSS 11.5 was applied to calculate the statistical significance of differences in the mRNA expression of the respective genes between thyroid tissues (Fuhrer et al. 2005, Krause et al. 2007a,b).

\section{Confocal laser scanning microscopy}

FRTL-5 cells were grown on coverslips $\left(1 \times 10^{5} /\right.$ well $)$. Experiments were performed as described under cell culture. Subsequently, the cells were permeabilized and fixed with $0.01 \%$ Triton X-100 in $2 \%$ paraformaldehyde/PBS (all from Sigma-Aldrich) for $20 \mathrm{~min}$ on ice. Afterward, the cells were washed three times with PBS followed by incubation with the primary antibodies overnight at $4{ }^{\circ} \mathrm{C}$ with $0.1 \%$ BSA in PBS (FOXO3a, 1:1000; anti-phospho-FOXO3a, 1:1000). After washing the cells three times with PBS, the cells were incubated for $1 \mathrm{~h}$ with the secondary anti-rabbit Alexa Fluor 488 antibody (Molecular Probes, Eugene, OR, USA) diluted at 1:1000 in PBS. Confocal analysis was performed on a confocal laser scanning system (TCS SP2; Leica, Wetzlar, Germany) attached to a microscope $(100 \times$ oil immersion lens; PL Fluotar 1.3; Leica). Optical sections $(0.45 \mu \mathrm{m})$ with approximately 150 cells were investigated.

\section{Western blot analysis}

Western blot analysis was performed using antibodies against FOXO3a (Cell Signaling, Charlottesville, VA, USA) and the phosphorylated form (Thr32) of FOXO3a, which represents the Akt phosphorylation site (van der Heide et al. 2004; Upstate Biotechnology, Lake Placid, NY, USA). Cells were lysed in buffer containing $10 \mathrm{mM}$ Tris, $400 \mathrm{mM} \mathrm{NaCl}, 1 \mathrm{mM}$ EDTA, and $0.1 \%$ NP-40 (all from Sigma). Fifty micrograms of protein were separated on $10 \%$ SDS gels followed by semi-dry western blotting. Subsequently, membranes were blocked with $5 \%$ BSA in TBST $(50 \mathrm{mM}$ Tris- $\mathrm{HCl}(\mathrm{pH} 7.5)$ and $150 \mathrm{mM} \mathrm{NaCl}$ containing $0.05 \%$ Tween 20). Blots were probed overnight with the following dilutions of antibodies in 5\% BSA containing TBST (10 mM Tris (pH 8.0), $150 \mathrm{mM}$ $\mathrm{NaCl}, 0.05 \%$ Tween-20): anti-FOXO3a (1:1000), anti-phospho-FOXO3a (1:750), anti-phospho-JNK (MAPK8) (1:1000), and anti- $\beta$-actin (1:750). After incubation with a secondary anti-rabbit antibody coupled to HRP (Cell Signaling), immunocomplexes were visualized by enhanced chemiluminescence (Pierce, Rockford, IL, USA). 


\section{Subcellular fractionation}

Subcellular fractionation was performed as described by Ni et al. (2007). Briefly, $3 \times 10^{5}$ FRTL- 5 cells were split into Petri dishes and grown to confluence. Subsequently, $400 \mu \mathrm{M} \mathrm{H}_{2} \mathrm{O}_{2}$ were added to full growth media (containing insulin, TSH, and NCS) and the cells were incubated for $4 \mathrm{~h}$. No hydrogen peroxide was added to the controls. Afterward, the cells were washed twice with ice-cold PBS, were shock frozen in liquid nitrogen, and stored at $-80^{\circ} \mathrm{C}$. The cells were then lysed in $250 \mu \mathrm{l}$ ice-cold lysis buffer containing protease/phosphatase inhibitors and centrifuged at $3000 \mathrm{~g}$ for $10 \mathrm{~min}$. The supernatant (containing the cytosolic protein fraction) was removed and mixed with $250 \mu \mathrm{l} 2 \times$ SDS sample buffer. The remaining pellet with the nuclear protein fraction was suspended in $500 \mu 11 \times$ SDS sample buffer. Equal volumes of the cytosolic and nuclear fraction were used for western blot analysis.

\section{Immunohistochemistry}

Paraffin-embedded tissue sections $(2 \mu \mathrm{m})$ were deparaffinized in xylol and subsequently pretreated in a microwave oven in $0.1 \mathrm{M}$ citrate buffer (pH 6) to allow antigen retrieval. For immunodetection, the LSAB + System (DAKO Cytomation, Hamburg, Germany) was used, according to the manufacturer's description. Briefly, slides were incubated with $3 \% \quad \mathrm{H}_{2} \mathrm{O}_{2}$ for $30 \mathrm{~min}$ followed by three washing steps with PBS including 1\% BSA (PBS/BSA; Sigma). Subsequently, unspecific binding was blocked for $30 \mathrm{~min}$ followed by treatment with a) polyclonal rabbit FOXO3a antibody and b) monoclonal rabbit phospho-Akt antibody (both diluted 1:500 in PBS; Cell Signaling). After incubation with a biotinylated secondary goat anti-rabbit antibody, the immunocomplexes were detected by streptavidin peroxidase and diaminobenzidine. The sections were counterstained with hemalaun and mounted on AquaTex (Merck, Darmstadt, Germany). Positive controls were performed with tissue sections from small intestine (FOXO3a) and colon cancer (phospho-Akt) respectively.

Analysis of FOXO3a and pAkt protein staining was done by two independent investigators (SK/DF). Semiquantitative analysis of FOXO3a and pAkt was performed using the percentage of positively stained thyrocytes/ten randomly selected sections/slide (200X magnification, duplicate). The staining index was calculated for each tissue sample and expressed as follows: $0=0 \%$ staining, $1 \geq 25 \%$ staining, $2=25-50 \%$ staining, $3=50-75 \%$ staining, and $4 \geq 75 \%$ staining.

\section{Results}

\section{Effects of thyroid-specific growth factors and signaling cascades on FOXO3a function}

\section{Differential modulation of FOXO3a localization by TSH and insulin}

In the thyroid, three different pathways regulate thyrocyte proliferation and differentiation: the TSH/cAMP/PKA, the insulin/PI3K/Akt, and the PKC signaling pathway (Roger \& Dumont 1984, Medina \& Santisteban 2000, Kimura et al. 2001).

In the first set of experiments, we analyzed the influence of TSH and insulin on FOXO3a function. To this aim, differentiated rat FRTL-5 cells were starved for $48 \mathrm{~h}(0.2 \%$ serum, without TSH and insulin). Subsequently, the cells were incubated with either $10 \mathrm{mU} / \mathrm{ml} \mathrm{TSH}, 100 \mathrm{ng}$ insulin, 5\% serum, or full growth media (containing serum, TSH and insulin) for $8 \mathrm{~h}$. Western blot analysis and confocal microscopy were applied to investigate FOXO3a activation.

Compared with FRTL-5, the cells kept in normal growth media, $48 \mathrm{~h}$ of starvation led to a decrease in FOXO3a phosphorylation and to strong nuclear accumulation of FOXO3a (Fig. 1). In the following experiments, this starvation condition was used as a control.

Subsequent addition of $10 \mathrm{mU} / \mathrm{ml} \mathrm{TSH}$ did not change phosphorylation of the insulin-PI3K/Akt phosphorylation site Thr32, and calization compared with starved cells, but resulted in a marginal increase in total FOXO3a (Fig. 1B). By contrast, insulin and serum strongly induced FOXO3a Thr32 phosphorylation and nuclear exclusion of FOXO3a. The presence of all growth factors in the full growth media exerted an additive effect on FOXO3a phosphorylation (Fig. 1A and B).

\section{Differential modulation of FOXO3a transcriptional activity by TSH and insulin}

Next, we addressed the question, whether the observed shift in FOXO3a localization after growth factor stimulation correlates with alteration in FOXO3a target gene transcription. The mRNA expression of p27kip and Bim was significantly inhibited after treatment with insulin, serum, or growth media compared with the starving control (for all $P<0.01$ ). By contrast, treatment of cells with TSH did not significantly alter mRNA expression of p27kip and Bim compared with starved controls (Fig. 1C).

Furthermore, starving media and TSH appeared to be correlated with the inhibition of FOXO3a-dependent GADD45A transcription, while insulin, serum, and growth media significantly induced $G A D D 45 A$ mRNA expression $(P<0.001$; Fig. 1C). 
A

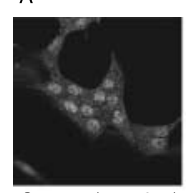

Control (starving)

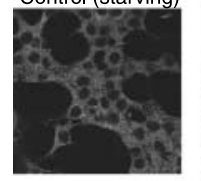

Serum

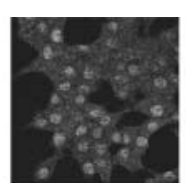

TSH

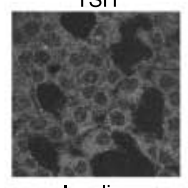

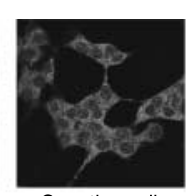

Growth media
B

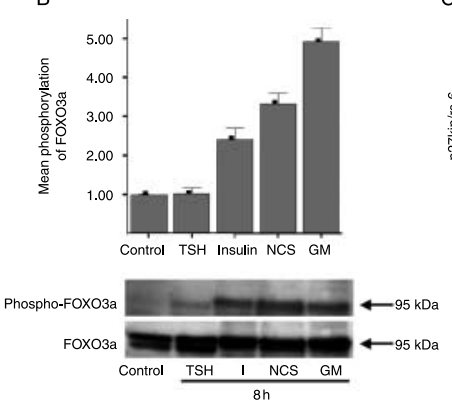

C

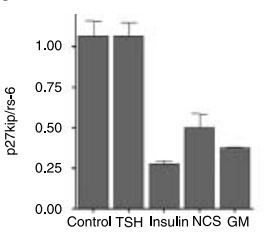

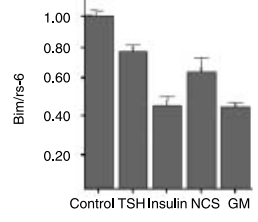

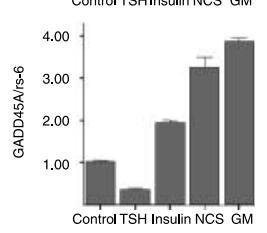

Figure 1 Regulation of FOXO3a localization and function by different growth factors. (A) Confocal microscopy shows that control cells cultured under starving conditions exhibit nuclear accumulation of FOXO3a, which could not be altered by TSH treatment. Conversely, insulin, serum, and full growth media induced nuclear exclusion of FOXO3a and its accumulation in the cytoplasm. (B) Histograms representing the extent of FOXO3a phosphorylation in response to growth factor stimulation. Starving conditions induced a decrease in FOXO3a phosphorylation, whereas addition of insulin, serum, or full growth media increases FOXO3a phosphorylation. TSH stimulation did not significantly alter FOXO3a phosphorylation and localization compared with starved cells. (C) Incubation with serum, insulin, and growth media induced a reduction in p27kip and Bim mRNA expression compared with TSH stimulation and starvation $(P<0.01)$. By contrast, insulin, $5 \%$ serum, and full growth media significantly stimulated GADD45A mRNA expression compared with TSH incubation and starvation $(P<0.001)$. FRTL5 cells were starved for $48 \mathrm{~h}(0.2 \%$ serum, without TSH and insulin; control) prior to incubation with either $10 \mathrm{mU} \mathrm{TSH}, 100 \mathrm{ng}$ insulin, 5\% newborn calf serum (NCS), full growth media containing insulin, NCS, and TSH (GM), or new starving media (Control) for $8 \mathrm{~h}$. Experiments were performed in duplicate and repeated independently three times. Gene expression was normalized to rs6 mRNA expression and quantified as described in Materials and Methods section.

\section{FOXO3a expression and activity is differentially regulated by PI3K versus PKA and PKC}

To confirm the observed distinct regulation of FOXO3a activity by TSH and insulin, FRTL-5 cells were grown in full growth media, which resulted in an exclusive cytoplasmatic FOXO3a expression and FOXO3a Thr32 phosphorylation (Fig. 2A). Subsequently, the cells were stimulated with activators or inhibitors of the cAMP, $\mathrm{PI} 3 \mathrm{~K} / \mathrm{Akt}$, and PKC signaling pathways. First, induction of the adenylate cyclase by $5 \mu \mathrm{M}$ forskolin for $4 \mathrm{~h}$ led to a nuclear shift of FOXO3a (Fig. 2A), but this did not result in altered target gene expression. Second, neither the stimulation of PKC with PMA nor its inhibition with GF10923X had an effect on FOXO3a localization (data not shown). Third, inhibition of the PI3K/Akt signaling pathway by LY294002 reversed the effect of insulin on FOXO inactivation and resulted in a nuclear FOXO3a accumulation, and decreased the fraction of FOXO3a phosphorylation (Fig. 2A) and a significant increase in the mRNA expression of the FOXO3a target genes, p27kip $(P<0.01)$ and $\operatorname{Bim}(P<0.01)$, compared with the untreated control (Fig. 2B). By contrast, GADD45A mRNA expression was significantly downregulated $(P<0.05$; Fig. 2B).

\section{Oxidative stress results in increased JNK phos- phorylation and FOXO3a activation}

Thyrocytes are frequently exposed to free radicals that are a side product of $\mathrm{TH}$ synthesis with hydrogen peroxide required as an essential cofactor. To analyze
FOXO3a activation upon oxidative stress in the thyroid, FRTL-5 cells were treated with $400 \mu \mathrm{M}$ $\mathrm{H}_{2} \mathrm{O}_{2}$ for different periods of time. Control cells were kept in full growth media and showed an exclusive cytoplasmatic FOXO3a expression, which correlated with strong FOXO3a (Thr32) phosphorylation (Fig. 3A and $\mathrm{B}$ ). Prolonged exposure of FRTL-5 cells with $400 \mu \mathrm{M} \mathrm{H} \mathrm{H}_{2} \mathrm{O}_{2}$ resulted in a nuclear accumulation of FOXO3a and a significant decrease in phosphorylated FOXO3a (Thr32) in the cytoplasm as shown by confocal microscopy (Fig. 3A and B).

In addition, subcellular fractionation was performed and confirmed the decrease in phosphorylated FOXO3a exclusively in the cytoplasm with a combined reduction in total cytoplasmatic FOXO3a after $\mathrm{H}_{2} \mathrm{O}_{2}$ treatment (Fig. 3C). As expected, phosphorylated FOXO3a was absent in the nuclear fraction of controls kept in the growth media (Fig. 3C). Moreover, as a functional readout of FOXO3a activation by oxidative stress, we found a time-dependent increase in the mRNA expression of FOXO3a target genes p27kip, followed by an increase in GADD45A transcription after treatment of FRTL-5 cells with $400 \mu \mathrm{M} \mathrm{H} \mathrm{H}_{2} \mathrm{O}_{2}$ (Fig. 3D).

Analysis of JNK, which has been described as a FOXO signaling partner in other cell systems, showed that increasing $\mathrm{H}_{2} \mathrm{O}_{2}$ concentrations $(400$ and $800 \mu \mathrm{M}$ for $240 \mathrm{~min}$ ) led to increased JNK phosphorylation in parallel with the above-described alterations in FOXO localization and activity (Fig. 3B). 
A
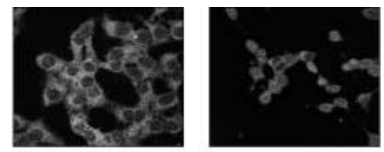

$5 \mu \mathrm{m}$ forskolin
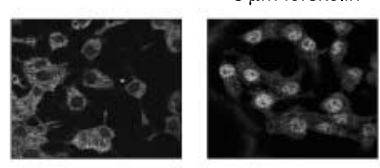

LY294002
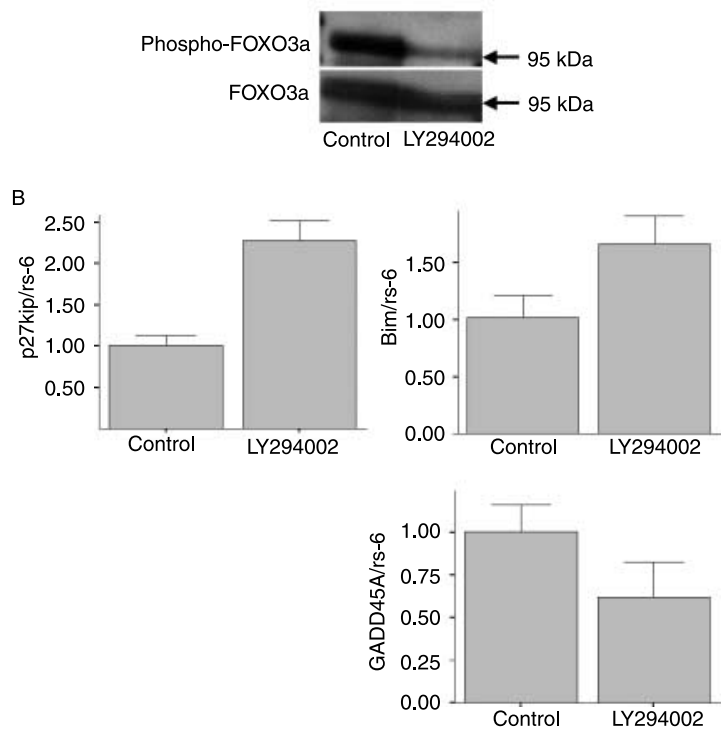

Figure 2 FOXO3a expression and activity is differentially regulated by PKA and PI3K. (A) Treatment of FRTL-5 cells with $5 \mu \mathrm{M}$ forskolin for $24 \mathrm{~h}$ led to a nuclear shift of FOXO3a, but this did not result in target gene transcription (data not shown), most likely due to a toxic effect of massive cAMP stimulation through forskolin + TSH. A nuclear FOXO3a shift was also observed after inhibition of PI3K by $10 \mu \mathrm{M}$ LY294002 and was accompanied by decreased phosphorylation of $\mathrm{FOXO} a \mathrm{a}$ and (B) increased transcription of the FOXO3a target genes p27kip and Bim, but repression of $G A D D 45 A$ (for all $P<0.02$ ). FRTL5 cells were grown in full growth medium (containing insulin, NCS, and $\mathrm{TSH}$; control) and were incubated with activators of PKA (forskolin) and inhibitors of PI3K (LY294002) for 8 h. Experiments were performed in duplicate and repeated independently three times. Gene expression was normalized to rs 6 mRNA expression and quantified as described in the Materials and Methods section.

\section{Expression and transcriptional activity of FOXO3a in thyroid pathologies}

Distinct expression and localization of $\mathrm{FOXO3a} \mathrm{in}$ normal thyroid, follicular adenoma, and thyroid carcinoma

In order to assess the mRNA expression of FOXO3a, we performed quantitative real-time PCR on a panel of NT, FA, and (FTC, PTC). The mRNA of FOXO3a was significantly downregulated in PTC $(P<0.001)$ compared with benign thyroid tumors and normal thyroid tissue (Fig. 4A). In FTC, FOXO3a mRNA levels were also decreased compared with benign thyroid tumors and NT, but this failed to reach statistical significance $(P<0.08)$.

Subsequently, we investigated FOXO3a protein expression and subcellular localization by immunohistochemistry (Fig. 4B). As demonstrated in Fig. 4C, there is no difference in FOXO3a expression and localization between FA and NT presenting abundant nuclear FOXO3a expression. By contrast, in differentiated thyroid carcinoma (FTC and PTC), a marked cytoplasmatic FOXO3a localization was found, either in addition to nuclear staining (PTC) or with significantly reduced nuclear staining (FTC; Fig. 4B and C).

\section{Correlation between pAkt expression and cyto- plasmatic localization of FOXO3a in thyroid carcinoma}

Recently, deregulation of the PI3K/Akt pathway has emerged to play a fundamental role in thyroid carcinogenesis (Paes \& Ringel 2008). Since we observed an inhibitory impact of the PI3K/Akt pathway on FOXO3a activity in vitro, we were interested to know whether this regulatory principle might also apply in vivo. Therefore, we performed immunohistochemistry on the same panel of samples already analyzed for FOXO3a protein expression. Thyroid cancers displayed a strong pAkt staining intensity in $65 \%$ of the investigated FTC and in $70 \%$ of PTC. With the exception of two FTC, all thyroid carcinoma with cytoplasmatic FOXO3a expression showed simultaneously increased Akt phosphorylation. By contrast, pAkt expression was very faint and present in less than $13 \%$ of FA and less than $5 \%$ of normal thyroids, and this was correlated with an exclusive nuclear $\mathrm{FOXO} 3$ a localization in these tissues.

Figure 4B shows a representative image of FOXO3a and pAkt expression in normal thyroid tissue, follicular adenoma, and follicular and papillary thyroid cancer.

\section{Differential regulation of $\mathrm{FOXO3a} \mathrm{target} \mathrm{genes} \mathrm{in}$ thyroid carcinoma}

FOXO3a activity is reflected by target gene transcription, e.g., of Bim, GADD45A, and p27kip. To investigate whether the different expression and the distinct localization of FOXO3a in normal thyroids, benign, and malignant thyroid pathologies correlates with the mRNA expression of FOXO3a-related target genes, we analyzed the mRNA expression of $G A D D 45 A$, Bim, and p27kip in our series of 68 thyroid specimen.

The mRNA expression of p27kip was significantly reduced in thyroid carcinoma compared with benign thyroid tumors and normal thyroid tissue $(P<0.0001$; 
Fig. 5A). In line with this observation, Bim expression was also significantly decreased in malignant thyroid tumors compared with benign thyroid tumors and normal thyroid tissue $(P<0.02$, data not shown). By contrast, GADD45A was significantly upregulated in all thyroid cancers with the highest levels found in FTC $(P<0.0001$; Fig. 5B $)$.

\section{Discussion}

In this work, we investigated for the first time the regulation of FOXO3a in thyrocytes, in particular the influence of growth factors and hydrogen peroxide on

A FOXO3a

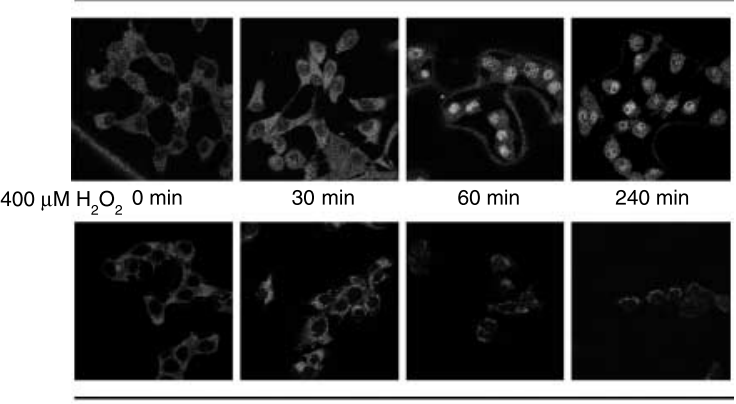

Phospho-FOXO3a

B

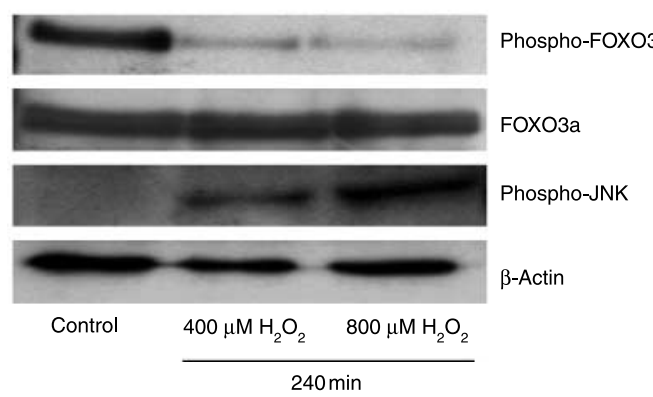

C
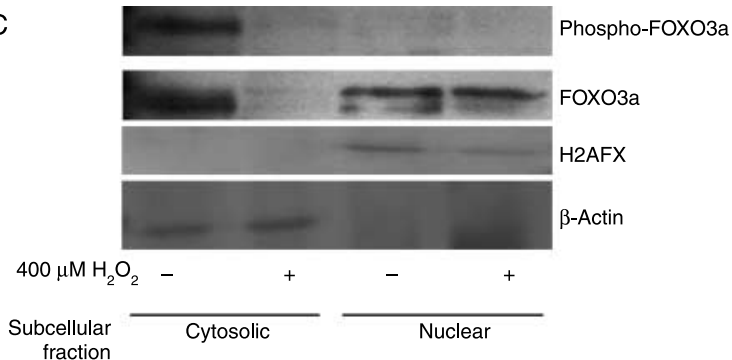
fraction

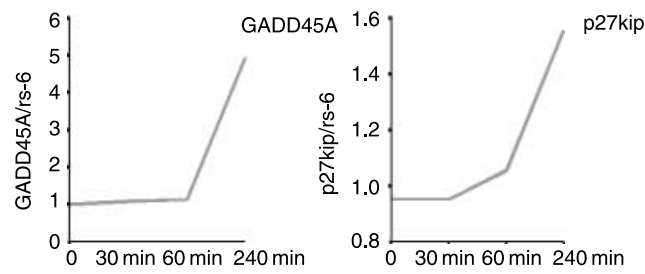

FOXO3a activation and function. In addition, we tried to elucidate the role of FOXO3a in thyroid tumorigenesis.

First, in vitro, we demonstrate that FOXO3a expression and activity is differentially regulated by the growth factors TSH and insulin: serum deprivation and stimulation with TSH led to decreased FOXO3a phosphorylation and to nuclear accumulation of FOXO3a, together with an increase in p27kip and Bim and a decrease in GADD45A mRNA expression. However, the effect of TSH on FOXO3a activity could only be observed on previously starved cells and could neither be mimicked by endogenous PKA activation with forskolin nor PKC activation with PMA. Hence, the data suggest that TSH has only a minor effect on FOXO3a activity.

By contrast, insulin induced opposing effects with an increased FOXO3a phosphorylation and cytoplasmatic accumulation in line with decreased transcription of Bim and p27kip and increased expression of GADD45A. This effect was confirmed by the inhibition of the PI3K/Akt pathway, which resulted in the upregulation of Bim and p27kip mRNA expression. These findings suggest insulin as a negative regulator of FOXO3a activity. However, in line with activation by insulin, abrogation of insulin signaling by LY294002 declined GADD45A mRNA expression. Thus, the apparent divergent responsiveness of GADD45A compared with p27kip and Bim upon insulin treatment suggests that GADD45A transcription directly depends on PI3K activation rather than on FOXO3a activation.

We next turned to the in vivo situation in order to study whether FOXO3a expression and function was

Figure 3 Activation of $\mathrm{FOXO} 3 \mathrm{a}$ by oxidative stress.

(A) Confocal microscopy using an anti-FOXO3a/anti-phosphoFOXO3a antibody showed nuclear translocation of FOXO3a in response to prolonged $\mathrm{H}_{2} \mathrm{O}_{2}$ treatment of FRTL-5 cells with a reduction in phosphorylation of $\mathrm{FOXO} 3 \mathrm{a}$ in these cells.

(B) Western blot analysis demonstrating that increasing concentrations of $\mathrm{H}_{2} \mathrm{O}_{2}$ induce JNK phosphorylation and FOXO3a dephosphorylation on Akt-sensitive phosphorylation sites in FRTL-5 cells. (C) Subcellular fractionation shows a marked decrease in cytoplasmatic phosphorylated FOXO3a and a reduction in cytoplasmatic FOXO3a after treatment of FRTL- 5 cells with $400 \mu \mathrm{M} \mathrm{H}_{2} \mathrm{O}_{2}$. As expected, phosphorylated FOXO3a was not detectable in the nuclear fraction of cells. To ensure the separation between the cytosolic and nuclear fraction antibodies against $\beta$-actin (cytosol) and $\mathrm{H} 2 \mathrm{AFX}$

(nucleus) were used. (D) Prolonged $\mathrm{H}_{2} \mathrm{O}_{2}$ treatment of FRTL-5 cells $>60 \mathrm{~min}$ led to a time-dependent induction of first p27kip, followed by GADD45A expression. FRTL5 cells were grown in full growth medium (containing insulin, serum, and TSH) and were incubated with $\mathrm{H}_{2} \mathrm{O}_{2}$ in a dose- and time-dependent manner. Experiments were performed in duplicate and repeated independently three times. Gene expression was normalized to rs 6 mRNA expression and quantified as described in the Materials and Methods section. 
A

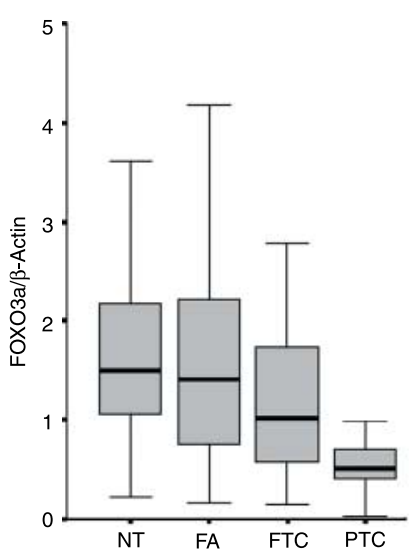

B

(a)

(b)

(c)

(d)

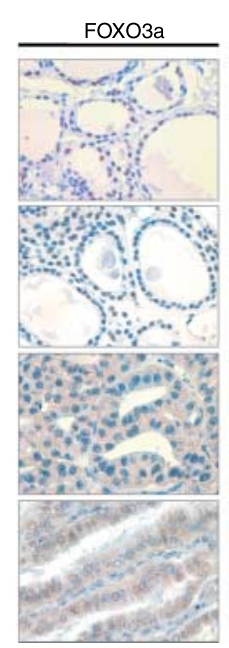

C

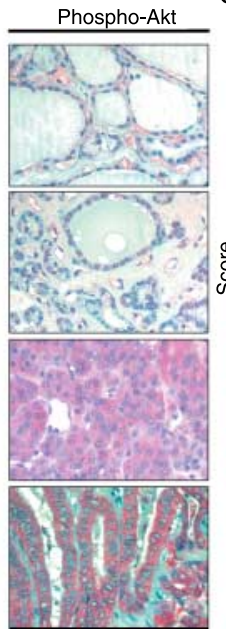

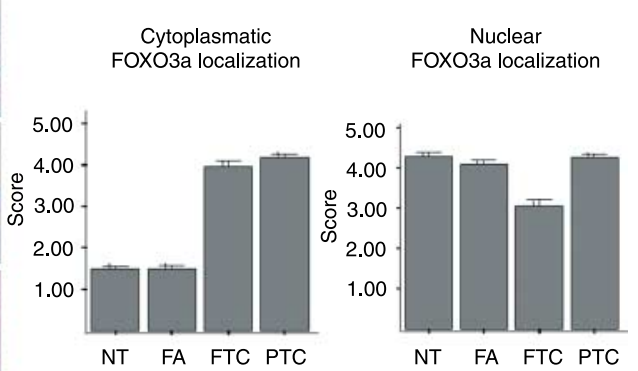

Figure 4 Analysis of FOXO3a and PI3K/Akt in thyroid tumors. (A) The mRNA expression of FOXO3a was analyzed in a panel of 22 normal thyroids (NT), 22 follicular adenomas (FA), 14 follicular thyroid carcinoma (FTC), and 10 papillary thyroid carcinoma (PTC). Results are presented in boxplots showing median and distribution (box area $=50 \%$ of samples) of FOXO3a mRNA expression normalized for $\beta$-actin (housekeeping gene). FOXO3a mRNA was significantly downregulated in PTC $(P<0.001)$ compared with benign thyroid tumors and normal thyroid tissue. In FTC, FOXO3a mRNA levels were also decreased compared with benign thyroid tumors and NT, but this failed to reach statistical significance $(P<0.08)$. (B) Immunohistochemical analysis using antibodies against FOXO3a and pAkt was performed in a series of 196 benign and malignant thyroid tumors including 65 follicular adenoma (FA), 68 follicular thyroid carcinoma (FTC), 63 papillary thyroid carcinoma (PTC) with adjacent normal tissue, and 19 normal thyroid tissues (NT). Representative images of FOXO3a and pAkt staining in (a) NT, (b) FA, (c) FTC, (d) PTC showing nuclear staining in NT and FA and strong cytoplasmatic staining either in addition to nuclear staining in PTC or with significantly reduced nuclear staining in FTC. Phospho-Akt: both thyroid cancers display a strong pAkt-staining intensity, while pAkt staining was very faint/absent in FA and in NT (magnification $400 \times$ ). (C) Histograms presenting the cytosolic and nuclear distribution of FOXO3a in 65 follicular adenoma (FA), 68 follicular thyroid carcinoma (FTC), 63 papillary thyroid carcinoma (PTC) with adjacent normal tissue, and 19 normal thyroid tissues (NT). Semiquantitative analysis was performed as described in the Materials and Methods section $(0=0 \%$ staining, $1 \geq 25 \%$ staining, $2=25-30 \%$ staining, $3=50-75 \%$ staining, $4 \geq 75 \%$ staining).

altered between benign and malignant thyroid tumors and normal thyroid tissue. We observed two aspects both pointing to impaired FOXO function: first, a downregulation of FOXO3a mRNA was found in thyroid cancers, reaching significance for PTC. Secondly, and most interestingly, we found a striking difference in the subcellular localization of FOXO3a in thyroid carcinoma compared with FA and normal thyroids: in differentiated thyroid carcinoma (FTC and PTC), a cytoplasmatic FOXO3a localization was found, either in addition to nuclear staining (PTC) or with significantly reduced nuclear staining (FTC). There was no difference in FOXO3a expression and localization between follicular adenoma and normal thyroid tissue. These data also fit well with the decreased mRNA expression of the FOXO3a target genes p27kip and Bim and increased GADD45A levels detected in the thyroid malignancies.

Several aspects emerging from our observations involve the insulin/PI3K/Akt pathway as an inhibitory switch of FOXO3a function. The finding of the increased expression of GADD45A in FTC and PTC despite the nuclear absence of FOXO3a correlates perfectly with the observed dependence of GADD45A on insulin/PI3K/Akt signaling. There is emerging evidence that the PI3K/Akt axis is constitutively active in many types of human cancer (Nicholson \& Anderson 2002). A deregulation of the PI3K/Akt activation can occur due to mutations or amplification of PI3K/Akt genes or as a result of decreased activity or loss of PTEN (Nicholson \& Anderson 2002). For instance, in thyroid cancer, it has been shown that the insulin/PI3K/Akt axis is frequently constitutively activated, e.g., by PI3KCA mutations and PI3KCA copy gains, as well as PTEN mutations in FTC (Dahia et al. 1997, Paes \& Ringel 2008). Moreover, PI3K/Akt signaling also appears to be involved in the progression of both papillary and follicular cancers to anaplastic thyroid cancers (Shinohara et al. 2007). A constitutive activation of the insulin/ IGF1/PI3K/Akt axis might explain the observed cytoplasmatic accumulation of FOXO3a leading to the inhibition of its transcriptional function, as demonstrated by the downregulation of p27kip and Bim in the thyroid carcinomas and in vitro after insulin stimulation. Furthermore, high levels of pAkt expression in FTCs and PTCs correlated with increased cytoplasmatic 

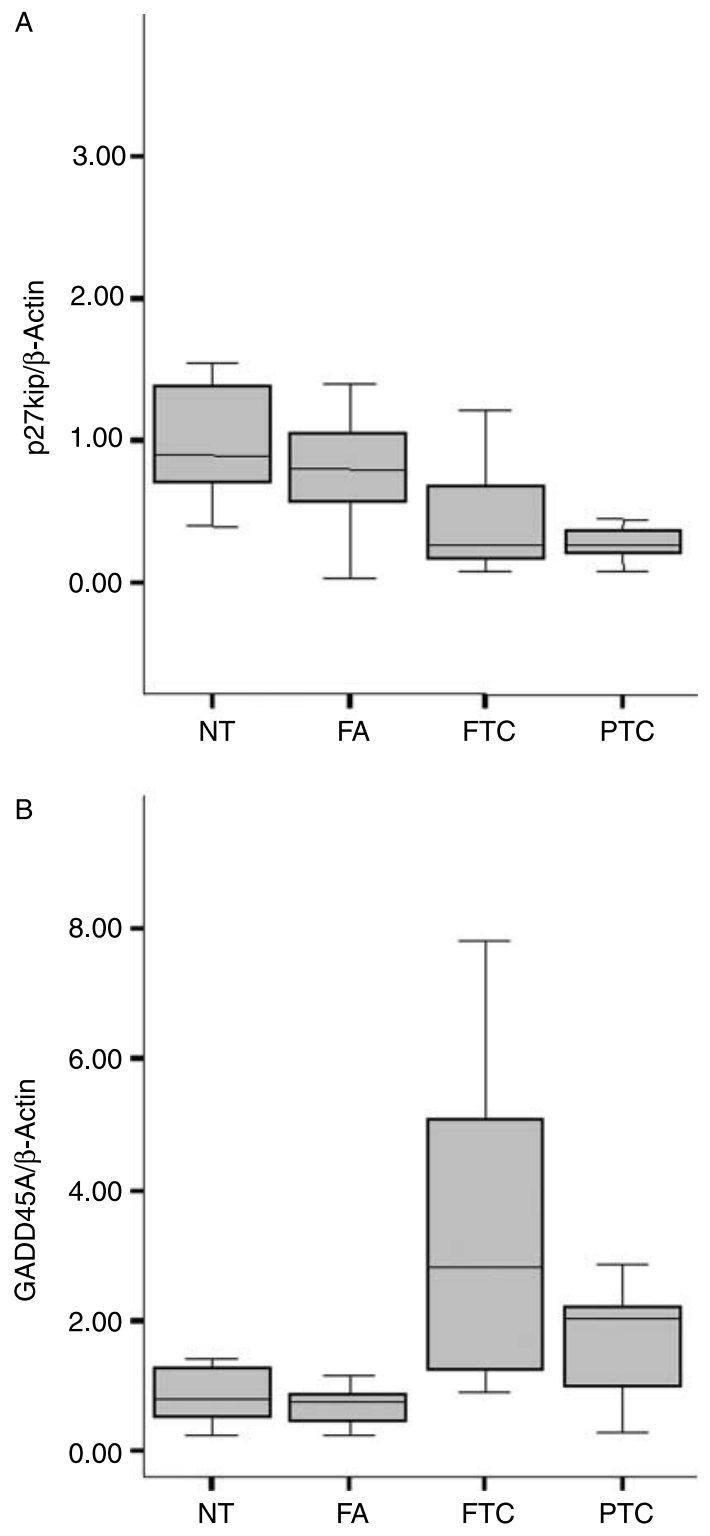

Figure 5 Analysis of mRNA expression of FOXO3a target genes in benign and malignant thyroid tumors. The mRNA expression of the FOXO3a target genes p27kip and GADD45A was analyzed in a panel of 22 normal thyroids (NT), 22 follicular adenoma (FA), 14 follicular thyroid carcinoma (FTC), and 10 papillary thyroid carcinoma (PTC). Results are presented in boxplots showing median and distribution (box area $=50 \%$ of samples) of FOXO3a mRNA expression normalized for $\beta$-actin (housekeeping gene). (A) p27kip mRNA expression is significantly downregulated in FTC and PTC compared with FA, NT; $P<0.001$. (B) GADD45A mRNA expression is significantly upregulated in FTC and PTC compared with NT and FA $(P<0.0001)$.

localization of FOXO3a in FTCs and PTCs. The pathophysiological consequences, however, at this state can only be speculative: our findings may suggest evidence for a novel escape mechanism from p27kip-induced cell cycle arrest and Bim-promoted apoptosis in thyroid cancer cells through pAkt-mediated inactivation of FOXO3a, thereby driving cancer cells from the inhibition of growth to cellular proliferation. A failure to induce cell cycle arrest at the G1/S boundary has already been shown in p27-deficient fibroblasts (Shinohara et al. 2007). In addition, it has been shown that Bim-/- lymphocytes are more resistant to cell death after cytokine withdrawal (Bouillet et al. 1999).

The observed upregulation of the growth arrest and DNA damage-inducible gene GADD45A in thyroid carcinomas is more difficult to explain since the function of $G A D D 45 A$ has been linked to growth control by induction of cell cycle arrest at the G2/M boundary, apoptosis, and DNA repair (Hollander et al. 1999, Wang et al. 1999, Tong et al. 2001). Several explanations for the observed GADD45A upregulation in thyroid carcinomas may have to be considered. First, GADD45A may be upregulated as a compensatory mechanism, which is yet ineffective due to other factors overriding cell cycle arrest (such as p27kip and Bim downregulation). Second, GADD45A may be non-functional due to mutations that have been reported for several types of human cancer (Yamasawa et al. 2002, Zerbini \& Libermann 2005). Third, instead of an exclusive tumor-suppressive role, overexpression of GADD45A may counterbalance DNA damagemediated apoptosis in cancer cells. For instance, in vitro models using bone marrow cells from GADD45A-deficient mice identified GADD45A as an anti-apoptotic gene, which increases the survival of hematopoietic cells upon u.v. radiation (Gupta et al. 2006). Fourth, GADD45A is also positively regulated by the PI3K/Akt signaling cascade and this appears to be independent of FOXO3a. Thus, we could demonstrate in FRTL-5 cells that GADD45A transcription is induced by the PI3K/Akt signaling cascade in response to insulin stimulation, whereas inhibition of the PI3K/Akt pathway by Ly294002 significantly reduced the expression of GADD45A mRNA. This dichotomous principle of GADD45A regulation has, to our knowledge, not hitherto been reported and will be the subject of future studies.

In conclusion, the data presented herein provide strong evidence for a novel mode of the insulin/IGF1 pathway in the regulation of thyroid cell proliferation and apoptosis by controlling sequestering of FOXO3a into the cytoplasm through phosphorylation. This effect is particularly apparent in FTCs and may be linked to constitutive activation of the PI3K/Akt pathway in these tumors. 


\section{Declaration of interest}

The authors declare that there is no conflict of interest that could be perceived as prejudicing the impartiality of the research reported.

\section{Funding}

This study was supported by the DFG (FU 356/3-1) and IZKF grants (B26) and by the Medical Faculty of the University of Leipzig (934000-363).

\section{Acknowledgements}

We thank Monika Gutknecht and Beate Jeßnitzer for excellent technical help.

\section{References}

Ambesi-Impiombato FS, Parks LA \& Coon HG 1980 Culture of hormone-dependent fuctional ephitelial cells from rat thyroids. PNAS 77 3455-3459.

Bartkova J, Horejsi Z, Koed K, Kramer A, Tort F, Zieger K, Guldberg P, Sehested M, Nesland JM, Lukas C et al. 2005 DNA damage response as a candidate anti-cancer barrier in early human tumorigenesis. Nature 434 864-870.

Birkenkamp KU \& Coffer PJ 2003 Regulation of cell survival and proliferation by the forkhead box, class O (FOXO) subfamily of forkhead transcription factors. Biochemical Society Transactions 31 292-297.

Bouillet P, Metcalf D, Huang DC, Tarlinton DM, Kay TW, Kontgen F, Adams JM \& Strasser A 1999 Proapoptotic Bcl-2 relative Bim required for certain apoptotic responses, leukocyte homeostasis, and to preclude autoimmunity. Science 286 1735-1738.

Brunet A, Sweeney LB, Sturgill JF, Chua KF, Greer PL, Lin Y, Tran H, Ross SE, Mostoslavsky R, Cohen HY et al. 2004 Stress-dependent regulation of FOXO transcription factors by the SIRT1 deacetylase. Science $\mathbf{3 0 3}$ 2011-2015.

Dahia PL, Marsh DJ, Zheng Z, Zedenius J, Komminoth P, Frisk T, Wallin G, Parsons R, Longy M, Larsson C et al. 1997 Somatic deletions and mutations in the Cowden disease gene, PTEN, in sporadic thyroid tumors. Cancer Research 57 4710-4713.

Dijkers PF, Medema RH, Lammers JW, Koenderman L \& Coffer PJ 2000a Expression of the pro-apoptotic Bcl-2 family member Bim is regulated by the forkhead transcription factor FKHR-L1. Current Biology 10 1201-1204.

Dijkers PF, Medema RH, Pals C, Banerji L, Thomas NS, Lam EW, Burgering BM, Raaijmakers JA, Lammers JW, Koenderman L et al. $2000 b$ Forkhead transcription factor FKHR-L1 modulates cytokine-dependent transcriptional regulation of p27(KIP1). Molecular and Cellular Biology 20 9138-9148.
Essers MA, Vries-Smits LM, Barker N, Polderman PE, Burgering BM \& Korswagen HC 2005 Functional interaction between beta-catenin and FOXO in oxidative stress signaling. Science 308 1181-1184.

Eszlinger M, Krohn K, Berger K, Lauter J, Kropf S, Beck M, Fuhrer D \& Paschke R 2005 Gene expression analysis reveals evidence for increased expression of cell cycleassociated genes and Gq-protein-protein kinase C signaling in cold thyroid nodules. Journal of Clinical Endocrinology and Metabolism 90 1163-1170.

Fagin JA 2002 Minireview: branded from the start-distinct oncogenic initiating events may determine tumor fate in the thyroid. Molecular Endocrinology 16 903-911.

Fuhrer D, Eszlinger M, Karger S, Krause K, Engelhardt C, Hasenclever D, Dralle H \& Paschke R 2005 Evaluation of insulin-like growth factor II, cyclooxygenase-2, ets-1 and thyroid-specific thyroglobulin mRNA expression in benign and malignant thyroid tumours. European Journal of Endocrinology 152 785-790.

Greer EL, Oskoui PR, Banko MR, Maniar JM, Gygi MP, Gygi SP \& Brunet A 2007 The energy sensor AMP-activated protein kinase directly regulates the mammalian FOXO3a transcription factor. Journal of Biological Chemistry $\mathbf{2 8 2}$ 30107-30119.

Gupta SK, Gupta M, Hoffman B \& Liebermann DA 2006 Hematopoietic cells from gadd45a-deficient and gadd45b-deficient mice exhibit impaired stress responses to acute stimulation with cytokines, myeloablation and inflammation. Oncogene 25 5537-5546.

van der Heide LP, Hoekman MF \& Smidt MP 2004 The ins and outs of FoxO shuttling: mechanisms of FoxO translocation and transcriptional regulation. Biochemical Journal 380 297-309.

Hildesheim J, Bulavin DV, Anver MR, Alvord WG, Hollander MC, Vardanian L \& Fornace AJ Jr 2002 Gadd45a protects against UV irradiation-induced skin tumors, and promotes apoptosis and stress signaling via MAPK and p53. Cancer Research 62 7305-7315.

Hollander MC, Sheikh MS, Bulavin DV, Lundgren K, Augeri-Henmueller L, Shehee R, Molinaro TA, Kim KE, Tolosa E, Ashwell JD et al. 1999 Genomic instability in Gadd45a-deficient mice. Nature Genetics 23 176-184. van der Horst A \& Burgering BM 2007 Stressing the role of FoxO proteins in lifespan and disease. Nature Reviews. Molecular Cell Biology 8 440-450.

Huang H \& Tindall DJ 2006 FOXO factors: a matter of life and death. Future Oncology 2 83-89.

Kimura T, Van Keymeulen A, Golstein J, Fusco A, Dumont JE \& Roger PP 2001 Regulation of thyroid cell proliferation by tsh and other factors: a critical evaluation of in vitro models. Endocrine Reviews 22 631-656.

Krause K, Karger S, Gimm O, Sheu SY, Dralle H, Tannapfel A, Schmid KW, Dupuy C \& Fuhrer D 2007a Characterisation of DEHAL1 expression in thyroid pathologies. Experimental Cell Research 156 295-301. 
Krause K, Karger S, Schierhorn A, Poncin S, Many MC \& Fuhrer D 2007b Proteomic profiling of cold thyroid nodules. Endocrinology 148 1754-1763.

Kroll TG, Sarraf P, Pecciarini L, Chen CJ, Mueller E, Spiegelman BM \& Fletcher JA 2000 PAX8-PPARgamma1 fusion oncogene in human thyroid carcinoma (corrected). Science 289 1357-1360.

Lee YJ, Lee JH \& Han HJ 2006 Extracellular adenosine triphosphate protects oxidative stress-induced increase of p21(WAF1/Cip1) and p27(Kip1) expression in primary cultured renal proximal tubule cells: role of PI3K and Akt signaling. Journal of Cellular Physiology 209 802-810.

Maier J, van Steeg H, van Oostrom C, Karger S, Paschke R \& Krohn K 2006 Deoxyribonucleic acid damage and spontaneous mutagenesis in the thyroid gland of rats and mice. Endocrinology 147 3391-3397.

Medina DL \& Santisteban P 2000 Thyrotropin-dependent proliferation of in vitro rat thyroid cell systems. Experimental Cell Research 143 161-178.

Ni YG, Wang N, Cao DJ, Sachan N, Morris DJ, Gerard RD, Kuro O, Rothermel BA \& Hill JA 2007 FoxO transcription factors activate Akt and attenuate insulin signaling in heart by inhibiting protein phosphatases. PNAS $10420517-20522$.

Nicholson KM \& Anderson NG 2002 The protein kinase B/Akt signalling pathway in human malignancy. Cellular Signalling 14 381-395.

Nikiforova MN, Lynch RA, Biddinger PW, Alexander EK, Dorn GW, Tallini G, Kroll TG \& Nikiforov YE 2003 RAS point mutations and PAX8-PPAR gamma rearrangement in thyroid tumors: evidence for distinct molecular pathways in thyroid follicular carcinoma. Journal of Clinical Endocrinology and Metabolism 88 2318-2326.

Paes JE \& Ringel MD 2008 Dysregulation of the phosphatidylinositol 3-kinase pathway in thyroid neoplasia. Endocrinology and Metabolism Clinics of North America 37 375-387.

Roger PP \& Dumont JE 1984 Factors controlling proliferation and differentiation of canine thyroid cells cultured in reduced serum conditions: effects of thyrotropin, cyclic AMP and growth factors. Molecular and Cellular Endocrinology 36 79-93.

Santoro M, Melillo RM, Carlomagno F, Vecchio G \& Fusco A 2004 Minireview: RET: normal and abnormal functions. Endocrinology 145 5448-5451.

Shinohara M, Chung YJ, Saji M \& Ringel MD 2007 AKT in thyroid tumorigenesis and progression. Endocrinology 148 942-947.

Song Y, Driessens N, Costa M, De DX, Detours V, Corvilain B, Maenhaut C, Miot F, Van Sande J, Many MC et al. 2007 Roles of hydrogen peroxide in thyroid physiology and disease. Journal of Clinical Endocrinology and Metabolism 10 3764-3773.

Stahl M, Dijkers PF, Kops GJ, Lens SM, Coffer PJ, Burgering BM \& Medema RH 2002 The forkhead transcription factor FoxO regulates transcription of p27Kip1 and Bim in response to IL-2. Journal of Immunology 168 5024-5031.

Tong T, Fan W, Zhao H, Jin S, Fan F, Blanck P, Alomo I, Rajasekaran B, Liu Y, Holbrook NJ et al. 2001 Involvement of the MAP kinase pathways in induction of GADD45 following UV radiation. Experimental Cell Research 269 64-72.

Tront JS, Hoffman B \& Liebermann DA 2006 Gadd45a suppresses Ras-driven mammary tumorigenesis by activation of c-Jun NH2-terminal kinase and p38 stress signaling resulting in apoptosis and senescence. Cancer Research 66 8448-8454.

Wang XW, Zhan Q, Coursen JD, Khan MA, Kontny HU, Yu L, Hollander MC, O'Connor PM, Fornace AJ Jr \& Harris CC 1999 GADD45 induction of a G2/M cell cycle checkpoint. PNAS 96 3706-3711.

Yamasawa K, Nio Y, Dong M, Yamaguchi K \& Itakura M 2002 Clinicopathological significance of abnormalities in Gadd45 expression and its relationship to p53 in human pancreatic cancer. Clinical Cancer Research 8 2563-2569.

Zerbini LF \& Libermann TA 2005 GADD45 deregulation in cancer: frequently methylated tumor suppressors and potential therapeutic targets. Clinical Cancer Research 11 6409-6413. 